\title{
Desencanto, Abandono e Escassez: O Desafio da Formação de Professores de Matemática
}

\section{Disenchantment, Abandonment and Shortage: The Challenge of the Training of Mathematics Teachers}

\section{Lélia de Oliveira $\mathrm{Cruz}^{\mathrm{a}}$; Arno Bayer ${ }^{\mathrm{b}}$}

a Centro de Estudos Superiores de Caxias, Universidade Estadual do Maranhão, Caxias, Brasil - lcruz.cx@gmail.com b Universidade Luterana do Brasil, Canoas, Brasil - arnob@ulbra.br

Palavras-chave:

Formação do professor de matemática. Prática profissional. Escassez de professor.
Resumo: O presente trabalho é um recorte da pesquisa que investiga a opinião dos egressos de uma universidade pública do Maranhão, que, no momento, não exercem a docência, por opção própria. Fato este que traz para o campo profissional a escassez de professores para atender a demanda da Educação Básica. Problemática que desafia tanto os cursos de formação de professor quanto às autoridades educacionais na busca de ação/resposta, no sentido de despertar nos discentes (licenciandos) o desejo de assumir e permanecer na docência. Para a coleta de dados, utilizou-se um questionário que foi respondido por $73,17 \%$ dos licenciandos que cursavam os últimos períodos em 2014, e haviam cursado a disciplina Estágio Supervisionado. Os dados coletados apontaram para a necessidade da construção de competências que conferissem aos futuros professores, autonomia e segurança para enfrentar o confronto com as situações reais do exercício profissional e assim assumir e permanecer na docência.

Abstract: This work is part of a research that investigates the opinion of the graduates of a public university in Maranhão that at the time, not engaged in teaching, at its option. Fact, which brings to the professional field the shortage of teachers to meet the demand of basic education. Issue that challenges both the teacher-training courses as educational authorities in search of action / response, to awaken in students (undergraduates), the desire to take and stay in teaching. For the data collection, we used a questionnaire that was been answered by $73.17 \%$ of undergraduates, who were in the last periods in 2014, and they had attended the Supervised Internship discipline. The collected data pointed to the need to build skills that confer future teachers, autonomy and security to face the confrontation with the real situations of professional practice and thereby gain and remain in teaching. 


\section{Introdução}

Falar da formação de professor e, em particular, da preparação do professor de Matemática, remete-nos ao primeiro decênio do século XXI, quando a preocupação legal com a formação de professores se tornou evidente, em virtude da implantação de resoluções, diretrizes e pareceres que norteiam os princípios, os critérios e os procedimentos que devem ser observados na organização e/ou reestruturação dos cursos de formação de professores no Brasil.

No transcurso desse período, um dos documentos significativos são as Diretrizes Curriculares Nacionais, normatizadas pela Lei 9394/96, documento que impulsionou as Instituições de Ensino Superior (IES) a discutirem as propostas e a estruturação curricular dos cursos de formação de professores. Nessa abordagem foram debatidas questões derivadas das pesquisas desenvolvidas na área e das conferências desencadeadas no país, resultando em documentos que evidenciam particularidades a serem contempladas no processo de formação, a fim de garantir aos profissionais do ensino, competências para responder às exigências da sociedade. Logo, as instituições formadoras devem oportunizar a construção de saberes que respaldem os futuros professores para assumirem e enfrentarem os percalços da profissão.

Nessa perspectiva, compreender o alcance dos saberes construídos, na formação inicial do professor de Matemática, para a constituição do seu desenvolvimento docente, é fundamental, como diz Gatti, “[...] uma prática não depende apenas de conhecimentos e de competências cognitivas [...] mas também de uma postura profissional aberta, capaz de criar e ensaiar alternativas para os desafios que se apresentam" (2011, p. 25). Ainda, apoiada em Gatti (2009), a desvalorização e a pouca atratividade da/pela profissão são os fenômenos que têm contribuído com o "movimento de abandono da carreira docente" (SOUTO; PAIVA, 2013), e como consequência, reforçando a escassez de professores para atender a Educação Básica (GATTI, 2009).

As concepções anteriores foram determinantes na decisão de aprofundar estudos para compreender os fenômenos do desencanto e/ou falta de atratividade pela carreira docente. Fato que se instalou no cenário educacional brasileiro e que contribui na decisão dos licenciados do Curso de Matemática do Centro de Estudos Superiores de Caxias/Universidade Estadual do Maranhão - CESC/UEMA - de abandonarem e/ou não assumirem a docência como profissão.

O estudo é um recorte de uma investigação em andamento, que se fundamenta nas ideias de Gatti (2009, 2010, 2011), Lapo e Bueno (2003), Lemos (2009), Marcelo García (2011), Souto e Paiva (2013), alicerçado, ademais, em outros pesquisadores, que possam surgir no percurso, essenciais no aclaramento dessa temática. O escopo é investigar a opinião dos licenciandos e egressos do Curso de Matemática do CESC/UEMA que não estão na 
docência sobre as decisões de não assumir e não permanecer na profissão docente, assim como as causas que os levaram a tomar essa decisão.

A docência não é uma opção atraente para os jovens que buscam uma profissão (GATTI, 2009); por sua vez, a escassez de professores para atender a Educação Básica é confirmada em pesquisas realizadas no cenário nacional e internacional, conforme pode ser verificado em: Gatti (2011); $\operatorname{OCDE}^{1}$ (2006); TCU² (2014); $\mathrm{UNESCO}^{3}$ (2013). As pesquisas realizadas descortinam os desafios postos aos cursos de licenciatura e as autoridades educacionais para a reflexão e ação, no sentido de despertar nos discentes (licenciandos) o desejo de assumir e permanecer na docência. O artigo evolve a intenção de investigar a falta de atratividade e o desencanto pela profissão docente, uma constante para os professores egressos do Curso de Matemática do CESC/UEMA, fato confirmado pelo crescimento do número de licenciados que abandonaram e/ou não chegaram a assumir a docência.

\section{Desafio da licenciatura: formar, despertar e manter os licenciados em Matemática na docência}

Para discorrer sobre os desafios da formação do professor, é importante refletir sobre o significado etimológico da palavra desafio. Sua origem é latina, disfidare, que significa renunciar à própria fé. A significação do termo permite afirmar que o desafio da licenciatura, em especial da licenciatura em matemática, advém da declinação, da perda da fé na carreira de professor, e esta parte dos aspectos políticos, sociais e econômicos de como a carreira é percebida no cenário da Educação no Brasil.

Nesse contexto, um dos possíveis caminhos para viabilizar no licenciado o comprometimento com o exercício da profissão é pensar, discutir a "arquitetura" e a estruturação dos cursos de licenciatura, a fim de desenvolver um trabalho didático e pedagógico que venha despertar nos licenciandos a atratividade pela docência (GATTI, 2009). Assim, preparar professores para assumir e permanecer na atividade docente. Esse trabalho perpassa pelo "[...] conhecimento sobre como formar professores competentes para atuar no mundo atual" (GATTI, 2011, p. 15), apesar de não haver "[...] uma estrutura adequada de incentivos que apoiem e fortaleçam o desenvolvimento profissional” (GATTI, 2009, p. 233).

O desafio brasileiro, na concepção de Gatti (2011), consiste no desenvolvimento urgente de políticas que interfiram no sentido de evitar o declínio da profissão docente,

\footnotetext{
${ }^{1}$ Professores são importantes: atraindo, desenvolvendo e retendo professores eficazes (OCDE, 2006).

${ }^{2}$ Relatório (TCU, 2014).

${ }^{3}$ A Organização das Nações Unidas para a Educação, a Ciência e a Cultura (Unesco) estima que até 2030 serão necessários 8,4 milhões de professores para assegurar as necessidades educacionais de todas as crianças do ensino primário e secundário.
} 
valorizando o magistério e oportunizando às pessoas que optam pela docência, que sejam, de fato, assistidas na sua formação inicial e em seu desenvolvimento profissional.

Segundo refere Ponte, o desenvolvimento profissional se caracteriza "[...] como um movimento de dentro para fora [...] dando especial atenção às realizações do professor e ao que ele se revela capaz de fazer" $(2014$, p. 346) e este não se faz apenas pela acumulação de conhecimentos, mas pela capacidade de poder utilizá-los em seu processo de renovação constante. Esse, no entendimento de Nóvoa (1997), é o ponto de partida para estimular o pensamento autônomo, que se configura na reflexão crítica, conduzindo à autoformação participada, visando à conformação da identidade profissional.

Trabalhar na vertente do desenvolvimento da identidade profissional do professor de Matemática é o grande desafio que se apresenta às instituições formadoras. Por conseguinte, compreender o que é identidade profissional e como ela se desenvolve, pode ser o primeiro passo na busca de uma formação que desperte e/ou consolide no licenciando o desejo pela docência. Segundo observa Nóvoa (2007), o professor, ao optar pela profissão, precisa descobrir sua maneira de ser/estar na docência, encontrar sua identidade "uma espécie de segunda pele". Visto que, a identidade profissional "[...] é um lugar de lutas e de conflitos, é um espaço de construção de maneiras de ser e de estar na profissão. [...] realçando a maneira como cada um se sente e se diz professor" (NÓVOA, 2007, p. 16).

Como preparar professores para assumir e permanecer na docência? Entende-se que essa tarefa se localiza na função da formação inicial (graduação), e o fenômeno a ser vencido é a escassez de professores para atender a Educação Básica. Esse problema não é particularidade só nossa, ele extrapola os limites geográficos da realidade nacional. Conforme afirmam Gatti; Barreto e André, "no âmbito internacional [...] a escassez é registrada por vários países como resultado de uma profissão pouco atrativa” (2011, p. 16). Um estudo publicado pela Unesco ${ }^{4}$ reafirma a necessidade de investir na formação de professores para assumir e permanecer na profissão, ao divulgar que, até 2030, o mundo vai precisar de mais 8,4 milhões de professores, serão necessários 3,3 milhões de professores no Ensino Fundamental e 5,1 milhões no Ensino Médio5

Segundo demonstra relatório da $\mathrm{OCDE}^{6}$, duas grandes preocupações relativas à carreira docente, prevalecem entre os governantes de vários países. A primeira, relativa à "redução no número de professores" (2006, p. 185), a escassez quantitativa, e a segunda se refere à "retenção de professores eficazes" (2006, p. 180), profissionais com capacidade comprovada para exercer sua função. Inúmeras pesquisas têm contemplado a temática no

\footnotetext{
${ }^{4}$ Organização das Nações Unidas para Educação, Ciência e Cultura.

${ }^{5}$ Disponível em <http://memoria.ebc.com.br/agenciabrasil/noticia/2013-10-03> acessado em jan. 2015.

${ }^{6}$ Organização para Cooperação e Desenvolvimento Econômicos.
} 
Brasil, como pode ser observado em Lapo e Bueno (2003), Gatti (2009), Cruz (2013) e Lemos (2013). Outras têm olhado a escassez, provocada pelo desencanto que leva ao abandono de professores de Matemática para atender a Educação Básica, tais como Souto et al. (2010), Moreira et al. (2012), Souto e Paiva (2013) e Paz (2013).

No cenário nacional, algumas medidas vêm sendo trabalhadas pelo governo brasileiro, como o lançamento da "proposta estrutural e emergencial para o enfrentamento da escassez de professores no Ensino Médio” (BRASIL, 2007). Que objetiva estudar e viabilizar medidas para superar o déficit docente na Educação Básica. As recomendações do governo federal devem ser trabalhadas em colaboração com os Estados e Municípios (BRASIL, 2007, p. 11). Apesar das ações propostas, o problema persiste. Pois, em 2013, o TCU ${ }^{7}$, mediante auditoria, comprovou que faltam 32 mil professores com formação específica nas 12 disciplinas obrigatórias do Ensino Médio, e o quantitativo de professores formados a cada ano não supre o déficit atual.

O problema da escassez agrava-se ainda mais com a falta de atratividade pela docência. Um estudo realizado pela $\mathrm{OIT}^{8}$ e pela UNESCO, envolvendo 38 países, dentre eles o Brasil, revelou que diminui a cada ano o número de jovens que pretendem seguir a carreira do magistério (BRASIL, 2007). Fato constatado por Gatti, em pesquisa realizada com concludentes do Ensino Médio, em todas as regiões do país. Gatti (2009, p. 42) afirma que "apesar de [...] todo valor atribuído pelos estudantes à carreira docente [...] ela não representa uma possibilidade profissional para esses alunos". Os jovens ouvidos na pesquisa da autora, em geral, rejeitam a possibilidade de abraçar a carreira docente.

Com esse argumento, é possível sustentar que a falta de atratividade pelo magistério não é uma preocupação exclusiva do Brasil. O relatório da OCDE, que fornece análise abrangente sobre questões de políticas para professores em nível internacional, destaca que "muitos países enfrentam sérias dificuldades para recrutar professores qualificados em número suficiente". A preocupação que prevalece nos países é "atrair, desenvolver e reter professores eficazes" (2006, p. 3) na profissão, pressupostos que exigem investimento na formação inicial, com vistas a despertar no egresso o desejo de assumir e permanecer na profissão docente.

Nessa discussão destacamos a "queda de prestígio social da docência ao longo dos anos, que seria responsável pela maior dificuldade de recrutar pessoas talentosas para essa atividade" (OCDE, 2006, p. 83), acrescido do aumento das exigências impostas aos profissionais. Tomemos como exemplo o mal-estar dos professores em duas realidades

\footnotetext{
${ }^{7}$ Tribunal de Contas da União

${ }^{8}$ Organização Internacional do Trabalho.
} 
distintas. Na argentina, segundo o pensamento de Vollmer (2010) e no Canadá, apoiado em Lessard (2010).

Na Argentina, a Lei de Educação Nacional, conforme estudos de Vollmer (2010), estabelece maior investimento na formação e na ampliação " [...] dos direitos, deveres e obrigações dos docentes, e determina os objetivos gerais da formação, da especialização e da profissionalização docente ${ }^{9}$ ", na intenção de preparar os professores com capacidades para enfrentar os novos desafios profissionais. Ademais, o autor destaca que a partir de 2009 estão sendo desenvolvidas políticas educacionais para responder a referida Lei, fortalecendo a formação inicial dos professores, possibilitando responder os desafios. Enfrentamento que causa "[...] insegurança, desqualificação e crescente mal estar"10" (VOLLMER, 2010, p. 160). Dentro desse contexto, a criação dessa Lei reafirma a existência dos problemas enfrentados na profissão decente.

A seu turno, Lessard (2010) analisa a condição do trabalho docente no Canadá, país federal e, em Quebec ${ }^{11}$, uma província soberana em matéria de educação. Conforme o teórico, os docentes vivem pressionados por demandas múltiplas e contraditórias ${ }^{12}$, para que inovem suas práticas pedagógicas, para que sejam mais exigentes, envolvam e aprovem o maior número possível de alunos, dentre outros desafios. Resumindo em poucas palavras,

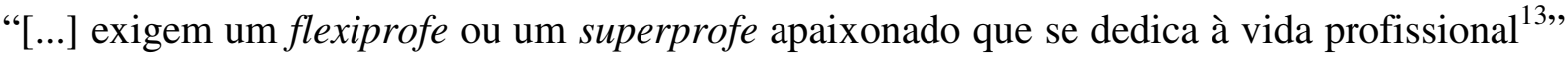
(LESSARD, 2010, p. 102), e da qual é obrigado a prestar contas.

Ao mesmo tempo, os professores canadenses “[...] precisam lutar para conservar o status da profissão, pois se encontram ameaçados por políticas de Estado que tornam o emprego no setor público precário e facilitam o crescimento do setor privado" (LESSARD, 2010, p. 103). E por não deterem mais o controle e o sentimento de eficácia com seu trabalho, em virtude das regulamentações do sistema educacional no Canadá e em Quebec, os professores percebem-se desvalorizados e perdem a confiança no seu trabalho, resultando em conflitos, resistência e mal-estar entre os docentes.

\footnotetext{
9 “[...] mayor precisión los derechos, deberes y obligaciones de los docentes, y determina los objetivos generales de la formación, la especialización y la profesionalización docente" (VOLLMER, 2010, p. 160).

10 "estar en mejores condiciones de superar un contexto de inseguridad, de desprofesionalización y de creciente malestar" (VOLLMER, 2010, p. 160).

${ }^{11} \mathrm{O}$ termo "Quebec designa somente o Quebec de língua francesa, ao passo que o termo Canadá designa todo o restante do país, incluindo o Quebec de língua inglesa” (LESSARD, 2006, p. 143).

12 "Los múltiples cambios: cultura de los jóvenes, pluralismo étnico y religioso, explosión de la masas de conocimientos, nuevas tecnologías de la comunicación, cultura popular de masas, exigencias de padres-usuarios y consumidores escolares, etc. Sea más exigente: transmisión de conocimientos y desarrollo de competencias. Y lucha contra el fracaso y el abandono escolar de los alumnos" (LESSARD, 2010, p. 102).

13،en pocas palabras ser un flexiprofe o un superprofe apasionado, al que se le va la vida y la personalidad en su profesión" (LESSARD, 2010, p. 102).]
} 
Com base nas duas realidades apresentadas, pode-se afirmar que o mal-estar e o desencanto que rondam os docentes é um dos fatores que fortalece a falta de atratividade dos licenciandos pela profissão. Nessa perspectiva, a docência precisa recuperar seu "status", sua imagem frente à sociedade e sua competitividade do mercado de trabalho, para se tornar uma profissão atraente para as novas gerações.

O relatório da OCDE (2006) preconiza que aos profissionais da educação devem ser viabilizadas condições de crescimento e amadurecimento profissional, com inter-relações maiores entre as etapas de formação inicial, iniciação na docência e desenvolvimento profissional. É importante destacar que compete aos professores “[...] preparar os estudantes para uma sociedade e uma economia em que se espera que sejam aprendizes auto direcionados, capazes e motivados a seguir aprendendo ao longo de toda a vida" (OCDE, 2006, p. 7). Nesse sentido, o exemplo repassado pelos professores aos estudantes deve ser positivo, marcado por entusiasmo e disposição com a atividade que desempenham, uma vez que exercem forte influência sobre a decisão dos alunos na escolha profissional.

No Brasil, entender como os professores concebem, identificam ou significam o seu desenvolvimento profissional no exercício da docência, bem como constituir a sua identidade profissional, são questões que têm orientado as pesquisas sobre formação de docentes no país, há cerca de duas décadas. Problema que tem adquirido relevância, a partir da promulgação da LDB nº 9394/96, quando, no Art. 61, parágrafo único, discrimina que:

\begin{abstract}
A formação dos profissionais da educação, de modo a atender às especificidades do exercício de suas atividades, bem como aos objetivos das diferentes etapas e modalidades da educação básica, terá como fundamentos: I - a presença de sólida formação básica, que propicie o conhecimento dos fundamentos científicos e sociais de suas competências de trabalho; II - a associação entre teorias e práticas, mediante estágios supervisionados e capacitação em serviço; III - o aproveitamento da formação e experiências anteriores, em instituições de ensino e em outras atividades. (BRASIL, 2015, p. 30)
\end{abstract}

Os referenciais legais têm como propósito a estruturação do que de mínimo de conhecimentos são necessários ao exercício da função docente, aliado à relação entre os aspectos teóricos e práticos da profissão, o que ocasionou a elaboração e aprovação das Diretrizes Curriculares para a Formação de Professores da Educação Básica (Resolução $\mathrm{CNE} / \mathrm{CP} \mathrm{n}^{\circ}$ 1/2002), que, no artigo relativo à organização curricular, destacam que "o ensino visando à aprendizagem do aluno" se ancora no desenvolvimento de estratégias metodológicas que garantam “o aprimoramento em práticas investigativas” (BRASIL, 2002, p. 1).

Nesse sentido, a formação deve ser pensada com a finalidade de capacitar os futuros professores para "organizar e dirigir situações de aprendizagem", condição necessária para garantir autonomia e segurança no início da carreira docente, podendo orientar o desenvolvimento profissional e, consequentemente, a constituição de uma identidade 
profissional, "[...] a qual garanta que esse se perceba como profissional da Educação" (PAIVA, 2006, p.89). Logo, a formação do futuro professor de Matemática precisa ser marcada por atividades que o orientem para o ingresso na atividade docente.

Em virtude da formatação do curso de licenciatura em Matemática que prioriza o conhecimento teórico em detrimento do pedagógico e das experiências, os egressos sentem dificuldades na articulação do fazer docente, por não terem construído, na graduação, habilidades/saberes que assegurem o desenvolvimento das competências profissionais complexas. Uma combinação de "habilidades, princípios e consciência do sentido e das consequências das práticas pedagógicas" (CONTRERAS, 2002, p. 83). Ou seja, competências que se concretizam no exercício profissional com autonomia, na qualidade do trabalho do professor e no compromisso com a aprendizagem dos alunos.

A qualidade da docência não é determinada apenas pela qualidade dos professores. O ambiente em que atuam exerce forte influência; por conseguinte, o apoio aos desafios, principalmente ao ingressarem no magistério, é fundamental aos professores, para que se desenvolvam e permaneçam na profissão. É preciso, também, a garantia de salários e condições de trabalho dignos para atrair os professores, pois "salários competitivos, boas condições de trabalho, satisfação no trabalho e oportunidades de desenvolvimento" (OCDE, 2006, p. 180) são essenciais na decisão de assumir e permanecer na profissão.

Nas últimas décadas, o destino profissional dos professores tem sido marcado por angústias, frustrações e desencantos que conduziram, em muitos casos, ao abandono da profissão. Essa problemática, dessa forma, reforça a falta ou a escassez de docentes para atender a Educação Básica. Apesar das particularidades de cada país, o relatório da OCDE destaca diretrizes de políticas comuns, embora haja diferenças entre as tradições de serviço público baseado em carreira e o baseado em posição. São elas:

A qualidade acima da quantidade de professores; Desenvolver perfil docente para alinhar o desenvolvimento e o desempenho dos professores as necessidades das escolas; Desenvolvimento do professor como um continuum; Tornar a educação do professor mais flexível; Transformar a docência em uma profissão rica em conhecimentos; Atribuir às escolas maior responsabilidade pelo gerenciamento da equipe decente (OCDE, 2006, p. 14).

Nesse sentido, o perfil delineado aos candidatos à profissão docente e, principalmente, aos candidatos a professor de Matemática, deve reunir amplo conhecimento dos saberes; das competências necessárias e das expectativas profissionais dos candidatos, para que, na elaboração do projeto de formação pelas IES, contemple o perfil do ingressante no Curso de Licenciatura em Matemática, além de aspectos tais como interesses, expectativas, dúvidas, origem social e cultural, valores e outros que possam ser ressignificados e não interfiram, negativamente, na formação. O princípio dessa ideia é que a Universidade é o lócus da formação inicial do docente e certamente "[...] a 'boa' formação na universidade produzirá a 
'boa' prática na escola” (MOREIRA et al., 2012, p. 10). Parâmetro importante para discussões da profissionalização docente, entretanto outros fatores poderão interferir no processo de desenvolvimento do profissional, apesar da compreensão de que uma boa formação acadêmica é uma condição necessária, contudo não é a única. Lemos (2009), nesse sentido, destaca que no próprio exercício da profissão podem ocorrer “[...] formas eufemizadas de abandono, um abandono em serviço que, gradativamente, evolui para um abandono definitivo". (LEMOS, 2009, p. 6). São táticas produzidas pelos professores que mesmo desencantados continuam na profissão até terem oportunidade de abandoná-la.

O pesquisador defende a participação ativa dos professores na formulação de políticas públicas para a fixação do docente à escola, a melhoria das condições de trabalho e a valorização profissional. Desse modo, tais ações podem contribuir para que os elevados índices de abandono e de itinerância diminuam.

Considerando o abordado, o pesquisador defende a participação ativa dos professores na formulação de políticas públicas para a fixação do docente à escola, a melhoria das condições de trabalho e a valorização profissional. Desse modo, tais ações poderiam contribuir para que os elevados índices de abandono e de itinerância diminuíssem.

Essa temática tem desafiado os cursos de licenciatura e as autoridades educacionais a buscarem soluções para "atrair, formar e manter bons professores nas escolas" (GATTI, 2009, p. 9), uma vez que "a evasão nos cursos de Licenciatura em todo país é excessivamente alta" (BRASIL, 2007, p. 11). Cabe, portanto, às instituições formadoras discutirem, elaborarem e desenvolverem propostas para minimizar o problema.

\section{A pesquisa}

O centro de ensino CESC/UEMA, desde a década de 1970, oferece cursos de formação de professores. Dentre esses, o curso de Ciências Licenciatura Curta, que, em atendimento às orientações legais, passou por diversas formatações e, em 2004, começou a funcionar com a denominação de Curso de Matemática Licenciatura, mediante Resolução n. ${ }^{\circ}$ 447/2002-CONSUN/UEMA.

A proposta pedagógica do curso apresenta “[...] inquietações com o alto índice de evasão dos cursos de Matemática no Brasil e a permanência do aluno durante muito tempo na universidade" (UEMA, 2015, p. 9). Outra inquietação é o fenômeno do desencanto e a falta de atratividade pela carreira docente. Fato constatado, em pesquisa realizada por Cruz (2013), com os egressos do curso de Matemática do CESC/UEMA, segundo evidencia o estudo, na última década, 63,87\% dos 155 licenciados não assumiram a docência, ou assumiram e depois abandonaram. 
Os dados da dissertação destacam o olhar dos licenciados, o que direcionou a questionar como o acadêmico, dos últimos anos, concebe essa temática. Considerando-se, ainda, a realidade internacional, de acordo com o relatório da OCDE (2006), a realidade brasileira, segundo relatório do TCU (2013) e as pesquisas realizadas em âmbito nacional, como pode ser observado em: (LEMOS, 2009; GATTI, 2010; LOUZANO et al., 2010; MOREIRA et al., 2012; CRUZ, 2013; PAZ, 2013; SOUTO, 2013) a questão do desencanto que converge para o abandono resultando na escassez de professores para atender a Educação Básica é o grande desafio dos cursos de formação, em especial, da formação de professores de Matemática.

A problemática é difícil e instigante; os dados da pesquisa, em andamento, trazem aspectos para refletir e procurar compreender o fato de alunos formados pelo Curso de Matemática do CESC/UEMA não buscarem a profissão docente, apesar de existir falta de professores de matemática na região. Nesse viés, foram selecionados 41 licenciandos que já haviam cursado Estágio Supervisionado, disciplina que possibilita um convívio com a sala de aula e com a realidade da profissão, logo estavam aptos a responderem o questionário.

A todos foi remetido/entregue - via email ou em mãos - um questionário, onde, 30 devolveram o instrumento respondido, perfazendo $73,17 \%$ do total dos licenciandos. Para este artigo, foram analisadas duas das questões abertas contidas no questionário. Os respondentes citados no texto foram identificados por um código formado por uma letra e um numeral, por exemplo, L03, e as suas falas ou posicionamentos, quando transcritos para o texto, serão grafados em itálico.

Os dados, depois de organizados, foram analisados à luz do referencial teórico na perspectiva da análise de conteúdo. Uma técnica que visa a descortinar mensagens, ou seja, “[...] conhecer aquilo que está por trás das palavras” (BARDIN, 2011, p. 50), tendo como fonte de consulta os dados tabulados, os resultados estão apresentados em quadros.

\section{Resultados e discussão}

No propósito de compreender a visão dos licenciandos sobre a pretensão de serem professores, como os acadêmicos justificam, a escolha do Curso e as expectativas com relação a ele foram analisadas as duas questões que compõem o questionário, previamente respondido por $73,17 \%$ dos graduandos. As respostas das questões selecionadas para este texto foram analisadas e discutidas a partir das ideias tecidas no texto.

Dos respondentes, 83,3\% trabalhavam e estudavam, destes $48 \%$ trabalhavam na profissão docente e estão em busca de certificação. Apenas um dos que já atuava na docência não pretendia continuar depois de formado. Dos 30 graduandos investigados, 73,3\% 
afirmaram que pretendem assumir a profissão docente; os demais dividiram-se entre os que não querem ser professor, $6,7 \%$, e os indecisos que somaram $20 \%$.

A discussão que segue apresenta os resultados das justificativas para a questão "Você pretende ser professor de Matemática?” Os resultados estão contemplados no Quadro 01.

Quadro 01 - Motivos apontados para justificar o desejo de ser professor de Matemática

\begin{tabular}{|c|l|c|c|}
\hline Código & Motivo & Frequência & $\%$ \\
\hline 1 & É a realização de um sonho, apesar da desvalorização & 3 & 10,0 \\
\hline 2 & Apesar de trabalhar em outra área não descarto a possibilidade & 2 & 6,8 \\
\hline 3 & Só se não passar em outro concurso & 4 & 13,3 \\
\hline 4 & É uma forma de contribuir com o que aprendi. & 3 & 10,0 \\
\hline 5 & Buscar mais conhecimentos especialização & 3 & 10,0 \\
\hline 6 & Só se puder conciliar com outra profissão & 1 & 3,3 \\
\hline 7 & Ainda não tenho convicção & 1 & 3,3 \\
\hline 8 & Me identifico com a área. & 4 & 13,3 \\
\hline 9 & Não respondeu & 9 & 30,0 \\
\hline TOTAL & & 30 & 100,0 \\
\hline
\end{tabular}

Fonte: A Pesquisa

Pela análise das respostas categorizadas, percebe-se que "[...] muitos alunos ingressam nos cursos de licenciatura com objetivos alheios à docência, o que gera uma significativa diferença entre a quantidade de formandos e os que realmente vão exercer a profissão" (SOUTO et al., 2010, p. 03).

De acordo com as respostas apresentadas no Quadro 01, 30\% dos licenciandos não justificaram se pretendem ser professor de Matemática, apesar de, anteriormente, 77,8\% dos que não justificaram afirmarem que pretendem assumir a docência ao concluir o curso. Dos que justificaram, 33,3\% demonstraram atratividade com a profissão nas respostas, ao destacarem: "é a realização de um sonho, apesar da desvalorização; é uma forma de contribuir com o que aprendi e me identifico com a área", para explicar o desejo de ser professor. A fim de reforçar o posicionamento dos licenciandos, extraíram-se algumas falas. O L13 argumentou: "Apesar do cansaço enorme, eu pretendo continuar. Ainda tenho uma variedade de dificuldades, porém, posso vencer esses desafios". O licenciando L17 declarou: "Embora o salário não seja tão atraente, lecionar é uma arte que sempre tive prazer em executar". Os licenciandos L13 e L17 já lecionam e pretendem continuar na profissão.

Os licenciandos sugerem na sua fala uma visão "fantasiosa" da profissão docente, quando citam “... é uma dádiva, ... é um dom, ... é uma arte, ... tenho vocação e gosto muito de lecionar”. Conforme destaca Moreira et al. (2012), “[...] parece que a profissão docente em si fica em segundo plano”. Essa visão romântica se desfaz com o ingresso na docência; é o "choque de realidade ${ }^{14}$ " (MARCELO GARCIA, 2006, p. 7), momento que, para muitos

\footnotetext{
14 "Ya resulta clásico el trabajo desarrollado por Simon Veenman (1984) quien popularizó el concepto de 'choque con la realidad' para referirse a la situación por la que atraviesan muchos docentes en su primer año de docencia” (MARCELO GARCIA, 2006, p. 7).
} 
ingressantes, representa a ruptura entre o que idealizavam e o que acontece na realidade da sala de aula e que pode certamente contribuir para o abandono da profissão.

A escolha da docência representa uma oportunidade de mudança de "status quo" por permitir a entrada imediata no campo profissional, como destaca o licenciando L07, "o mercado de trabalho para o professor de matemática é grande, oferece muitas oportunidades de trabalho", pensamento reforçado na argumentação do L11, "me identifico com a área e as oportunidades de emprego são maiores”. Os alunos L07 e L11 trabalham em áreas distintas da docência e buscam uma profissão para mudar sua situação social e financeira. Como afirma Gatti (2009, p. 13), “[...] os estudantes que optam pela docência tendem a ser de classe menos favorecida, o que corrobora também a perspectiva de busca de um salário imediato para sobrevivência, e o significado de ascensão social".

Analisando as respostas dos $20 \%$ indecisos, 66,7\% deles só assumem a docência se não passarem em outro concurso, e 33,3\%, se for possível conciliar com outra profissão mais rentável. Fica evidente nas afirmativas que os acadêmicos estão satisfeitos com o curso, apesar de a docência não ser a primeira opção profissional nem a mais atrativa, contudo é uma possibilidade que não descartam.

A indecisão dos respondentes encontra eco no depoimento dos licenciandos: L02 que afirma: "pretendo ser policial, se não conseguir, talvez venha ser professor". E o licenciando L21 reforçou que: "gostaria de conseguir outro emprego, algo mais rentável que me dê segurança financeira e, se possível, dar aulas também, futuramente prosseguir com meus estudos, minha formação na área”.

Os depoimentos apresentados deixam claro que, para esses alunos, o curso oportunizou a busca de conhecimentos e o preparo para enfrentar um concurso em outra área, conforme destacou o L21. Para o licenciando L02, docência é a última opção, ao afirmar: “quero ser policial, estou me preparando para o concurso, se não conseguir, talvez venha ser professor". Sua fala aponta a falta de atratividade para a profissão docente, "apesar de [...] todo valor atribuído à carreira docente [...] ela não representa uma possibilidade profissional para esses alunos" (GATTI, 2009, p. 42).

Em vista desses aspectos, avaliar "[...] os interesses, as expectativas, as dúvidas, a origem social e cultural, os valores - enfim, as condições gerais que afetam a opção pelo curso" (MOREIRA, et al. 2012, p. 25), pode contribuir para a elaboração de um projeto de formação que contemple, de alguma forma, o perfil dos ingressantes na licenciatura em Matemática, preparando-os para assumirem e, quem sabe até, permanecerem na docência.

As argumentações foram essenciais na identificação dos fatores que contribuíram para a escolha do curso. Conforme resultados expressados no Quadro 2. 
Quadro 02 - Escolha do curso de Licenciatura em Matemática

\begin{tabular}{|c|l|c|c|}
\hline Código & Motivo & Frequência & $\%$ \\
\hline 1 & Para aprender mais, sempre gostei das exatas & 7 & 23,3 \\
\hline 2 & Garantia de emprego devido à falta de profissional na área & 2 & 6,8 \\
\hline 3 & Gosto de Matemática & 8 & 26,6 \\
\hline 4 & A docência é a profissão mais importante & 3 & 10 \\
\hline 5 & Tenho afinidade com a área & 10 & 33,3 \\
\hline Total & 30 & 100 \\
\hline
\end{tabular}

Fonte: A Pesquisa

As respostas apresentadas à questão (Por que você escolheu o curso de licenciatura em Matemática?) reforçam e complementam as respostas à questão anterior (Você pretende ser professor de Matemática?). Pelo Quadro 02, verifica-se que 33,3\% dos respondentes afirmaram ter afinidade com a área. "Gostar de Matemática e para aprender mais e sempre gostei das exatas" foram os argumentos da escolha de 49,9\%, quase metade dos licenciandos investigados.

Somaram 16,8\% as respostas dos acadêmicos que acreditam ser a docência uma profissão possível, como pode ser observado nestes argumentos: "A docência é a profissão mais importante; Garantia de emprego devido à falta de profissional na área”. De modo geral, a opção da escolha do curso se deve "[...] à não oferta do curso de bacharelado na instituição, pois seria razoável imaginar que 'gostar de Matemática' levasse à escolha do bacharelado" (MOREIRA et al., 2012, p. 23). Na concepção de Moreira et al. (2012), a Matemática relevante para o professor (licenciatura) é distinta da Matemática (bacharelado); quem gosta de uma pode não gostar da outra.

As argumentações: "gosto de desafios e a Matemática me permite isso..., gosto de estudar e de trabalhar com números..., proporciona o desenvolvimento do raciocínio... e das opções que eu tinha na época do vestibular era o único que me identificava". Confirmam a concepção de Moreira et al. (2012), já citada. Dessa maneira, é possível observar que a escolha do curso de licenciatura se deve à falta da opção do bacharelado em Matemática, uma vez que a preferência é pelo conhecimento da Matemática, ficando o ensino da Matemática em segundo plano.

\section{Conclusão}

Este estudo teve por objetivo compreender até que ponto os fenômenos desencanto e/ou falta de atratividade pela carreira docente, que se instalaram no cenário educacional brasileiro, contribuem na decisão de licenciados do Curso de Matemática do Centro de Estudos Superiores de Caxias/Universidade Estadual do Maranhão - CESC/UEMA - de abandonarem e/ou não assumirem a docência como profissão. A ideia do recorte é apontar 
possíveis caminhos para que o acadêmico consiga enfrentar com segurança e autonomia os conflitos e desafios da profissão.

Os dados analisados sugerem que o Curso, desde o início, deve refletir sobre o que motiva os licenciandos a escolherem o curso de licenciatura, para, assim, melhor atender seus anseios e debilidades. Pela pesquisa, apesar de uma fala carregada de sonhos, de lamentações sobre a valorização, demonstra uma inclinação para o ser docente. $\mathrm{O}$ que direciona o curso de Matemática, desde a fase inicial, a trabalhar com seus acadêmicos essa necessidade. Para tanto, é fundamental enfatizar a realidade (MARCELO GARCIA, 2006), dando oportunidade para que o graduando estabeleça relação entre o conhecimento científico e a prática docente.

O que parece fundamental é o trabalho com uma docência comprometida com a formação de um professor crítico, com condições de atuar no contexto da escola atual. É fundamental proporcionar uma formação pautada em saberes relevantes para a constituição e o desenvolvimento de futuros professores, tendo claro que se está formando licenciados que, além de ter domínio do conhecimento específico de Matemática, devem ter, também, conhecimentos de como se aprende e de como se deve ensinar. Nesse sentido, os fundamentos sociológicos, filosóficos e didáticos são fundamentais para uma prática coerente e crítica.

Na pesquisa, 16,8\% dos acadêmicos acreditam na possibilidade de serem docentes. Apesar de ser um percentual pequeno, esse fato direciona ao indicativo de que, desde a gênese do curso, deverá acontecer uma ação conjunta de todos os professores formadores, a fim de possibilitar as condições necessárias para romper o ciclo da falta de atratividade, problema que fortalece o desencanto, culminando, na maioria das vezes, com a busca, do professor, por outras profissões.

Ademais, a pesquisa em andamento distingue outros fatores que têm motivado os egressos a abandonarem e/ou a não assumirem a docência. No entanto, os aspectos abordados já vislumbram, como trilha para o problema aqui destacado, o projeto pedagógico do curso e o trabalho coletivo dos formadores, tendo como premissa a docência na Educação Básica do nosso país.

\section{Referências}

BRASIL. CNE/CP Parecer 009/2001, de 8 de maio de 2001. Diretrizes Curriculares Nacionais para a Formação de Professores da Educação Básica. Brasília: Conselho Nacional de Educação, Ministério de Educação. 2001.

BRASIL. Ministério da Educação. Conselho Nacional de Educação. Escassez de professores no ensino médio: propostas estruturais e emergenciais. Brasília: MEC, 2007.

BRASIL. Tribunal de Contas da União. Relatório de Auditoria (Fiscalização no 177/2013). 2014. Disponível em: 
http://portal2.tcu.gov.br/portal/TCU/imprensa/noticias/arquivos/007.081-2013-ensino medio.pdf. Acessado em nov./2014.

BRASIL. Lei $n^{\circ}$ 9.394, de 20 de dezembro de 1996. Estabelece as diretrizes e bases da educação nacional. 11. ed. Brasília: Câmara dos Deputados, Edições Câmara, 2015. - (Série legislação; n. 159). Atualizada até 19/3/2015. Disponível em:

http://www.camara.leg.br/editora. Acesso em: nov. 2015.

CONTRERAS, J. Autonomia de professores. Trad.: Sandra Trabucco Valenzuela. São Paulo: Cortez, 2002.

CRUZ, L. de O. A formação do professor: a visão do licenciando e do egresso do curso de Licenciatura em Matemática do CESC/UEMA sobre a formação oferecida pelo curso para o exercício da docência. 2013, 141f. Dissertação de Mestrado - Programa de Pós-Graduação em Ensino de Ciências e Matemática, ULBRA, Canoas: RS. 2013.

DICIONÁRIO ETIMOLÓGICO Online. Disponível em:

http://www.dicionarioetimologico.com.br/. Acesso em 22 de novembro de 2015.

GATTI, B; TARTUCE, G. L. B. P; NUNES, M. M. R; ALMEIDA, P. C. A. Atratividade da carreira docente no Brasil. In: Estudos e Pesquisas Educacionais. São Paulo: Fundação Victor Civita, n. 1, 2010. p. 139-210. Disponível em: http://www.fvc.org.br/pdf/artigo-atratividadecarreira.pdf. Acesso em: março 2015.

GATTI, B; BARRETO, E. S. Professores do Brasil: impasses e desafios. Brasília: UNESCO, 2009.

GATTI, B. A Formação de professores no Brasil: características e problemas, Educação Sociedade, v.31, n.113, p.1355-1379, 2010. Disponível em: <http://www.cedes.unicamp.br>. Acesso em: 06 de abril de 2011.

GATTI, B; BARRETO, E. S; ANDRÉ, M. E. D. A. Políticas Docentes no Brasil: um estado de arte. Brasília. Representação no Brasil. 2011. 11-269. (Organização das Nações Unidas para a Educação, a Ciência e a Cultura). Disponível em:< http://unesdoc.unesco.org/images/0021/0021 21/212183.pdf> Acesso em: maio 2013.

LEMOS, J. C. G. Do encanto ao desencanto, da permanência ao abandono: o trabalho docente e a construção da identidade profissional. 2009. 315 f. Tese (Doutorado). Pontifícia Universidade Católica de São Paulo, São Paulo, 2009.

LESSARD, C. Gobernabilidad y políticas educativas, sus efectos sobre el trabajo docente: la perspectiva canadiense. In: OLIVEIRA, D. A; BORDÓN, J. O; CAVAROZZI, M; DIDRIKSSON, A; LESSARD, C; OLIVÉ, A. M; MORDUCHOWICZ, A; CRUZ, J. R; TEDESCO, J. C; VOLMER, M. I. Políticas Educativas y Territorios. Modelos de articulación entre niveles de gobierno. Buenos Aires: IIPE - UNESCO, 2010, p. 67-112. Disponível em: http://www.oei.es/historico/noticias/spip.php?article7268\&debut_5ultimasOEI=50. Acesso em: março 2015. 
MOREIRA, P. C; FERREIRA, E. B; JORDANE, A; NÓBRIGA, J. C. C; FISCHER, M. C. B; SILVEIRA, E; BORBA, M. C. Quem quer ser professor de matemática? Zetetiké: Revista de Educação Matemática, v. 20, n. 37, 2012. Disponível em:

http://ojs.fe.unicamp.br/ged/zetetike/article/view/2850/3729. Acesso em: março 2015.

NÓVOA, A. Formação de professores e profissão docente. In: NÓVOA, A. (org.). Os professores e sua formação. 3 ed. Portugal: Dom Quixote, 1997. p. 15-33.

NÓVOA, A. Os professores e as histórias da sua vida. In: NÓVOA, A. (org.) Vidas de professores. 2 ed. Portugal: Porto Editora, 2007. p. 11-30.

OCDE. Organização para Cooperação e Desenvolvimento Econômico. Professores são importantes: atraindo, desenvolvendo e retendo professores eficazes. São Paulo: Moderna, 2006.

PAIVA, M. A. O professor de Matemática e sua formação: a busca da identidade profissional in: NACARATO, A. M; PAIVA, M. A. V. A formação do professor que ensina Matemática: perspectivas e pesquisa. Belo Horizonte: Autêntica, 2006. p. 89-111.

PONTE, J. P. da. Práticas Profissionais dos Professores de Matemática. Portugal: Instituto de Educação da Universidade de Lisboa, 2014. Disponível em: www.ie.ulisboa.pt.

SOUTO, R. M. A; PAIVA, P. H. A. A. A pouca atratividade da carreira docente: um estudo sobre o exercício da profissão entre egressos de uma Licenciatura em Matemática. ProPosições, Campinas, v. 24, n. 1, p. 201-224, 2013. Disponível em: http://www.scielo.br/scielo.php?script=sci_arttext\&pid=S0103$73072013000100013 \& \operatorname{lng}=$ pt\&nrm=iso. Acesso em: marco 2015.

UNIVERSIDADE ESTADUAL DO MARANHÃO. Relatório de verificação do Curso de Ciências - Habilitação Matemática para reconhecimento. CESC/UEMA. Caxias, 1990.

VOLLMER, M. I. Acerca de las políticas de formación docente en la Argentina. In: OLIVEIRA, D. A; BORDÓN, J. O; CAVAROZZI, M; DIDRIKSSON, A; LESSARD, C; OLIVÉ, A. M; MORDUCHOWICZ, A; CRUZ, J. R; TEDESCO, J. C; VOLMER, M. I. Políticas Educativas Y Territorios. Modelos de articulación entre niveles de gobierno. Buenos Aires: IIPE - UNESCO, 2010. p. 159-164

\section{SOBRE OS AUTORES}

LÉLIA DE OLIVEIRA CRUZ. Possui graduação em Matemática pela Universidade Estadual do Maranhão (1988), graduação em Ciências pela Universidade Estadual do Maranhão (1986), graduação em Pedagogia pela Universidade Estadual do Maranhão (1993), mestrado em Ciências da Educação pelo convênio UEMA/IPLAC - Universidade Estadual do Maranhão/Instituto Pedagógico Latinoamericano Y Caribeño (1999) e mestrado em Ensino de Ciências e Matemática pela Universidade Luterana do Brasil. Atualmente é Professora Assistente IV da Universidade Estadual do Maranhão - Centro de Estudos Superiores de Caxias. Cursando doutorado em Ensino de Ciências e Matemática pela Universidade Luterana do Brasil (2013 - 2017). Tem experiência na área de Matemática, com ênfase em Ensino de 
Matemática, atuando principalmente nos seguintes temas: Educação Matemática, Educação Básica e Formação de professores.

ARNO BAYER. Possui graduação em Matemática pela Faculdade Porto Alegrense (1974) e doutorado em Educação pela Universidad Pontificia de Salamanca (1997). Atualmente é professor titular da Universidade Luterana do Brasil e professor orientador do Programa de Pós-Graduação em Ensino de Ciências e Matemática (PPGECIM) no Mestrado e Doutorado. Avaliador de Curso de Graduação e Avaliador Institucional do Sistema Nacional de Avaliação da Educação Superior. Tem experiência na área de Matemática, com ênfase em Matemática, atuando principalmente nos seguintes temas: Educação Estatística, Ensino Médio, Estatística e Educação Matemática.

Recebido: 22 de março de 2016.

Revisado: 12 de julho de 2016.

Revisado: 28 de julho de 2016.

Aceito: 25 de agosto de 2016. 